Article

\title{
Evaluation of Hydroxychloroquine Blood Concentrations and Effects in Childhood-Onset Systemic Lupus Erythematosus
}

\author{
Noël Zahr ${ }^{1, *, \dagger}$, Saik Urien ${ }^{2,+}{ }^{\text {, Christian Funck-Brentano }}{ }^{1} \mathbb{D}$, Hélène Vantomme ${ }^{1}$, Nicolas Garcelon ${ }^{3}$, \\ Isabelle Melki ${ }^{4}$, Margaux Boistault ${ }^{5}$, Olivia Boyer ${ }^{5}$ and Brigitte Bader-Meunier ${ }^{6}$
}

1 Clinical Investigation Center, Department of Pharmacology, INSERM, CIC-1901, UMR ICAN 1166, Pitié-Salpêtrière Hospital, Sorbonne Université, AP-HP, F-75013 Paris, France; christian.funck-brentano@aphp.fr (C.F.-B.); helene.vantomme@aphp.fr (H.V.)

2 Department of Pediatric and Perinatal Pharmacology, Necker Hospital, Université de Paris, AP-HP, F-75015 Paris, France; saik.urien@aphp.fr

3 Data Science Platform, INSERM UMR 1163, Imagine Institute, Université de Paris, AP-HP, F-75015 Paris, France; nicolas.garcelon@institutimagine.org

4 Infectious Disease and Internal Medicine Reference Center for Rheumatic, AutoImmune and Systemic Diseases in Children (RAISE), Department of General Pediatrics, Robert Debré Hospital, Nord-Université de Paris, AP-HP, F-75019 Paris, France; isabelle.melki@aphp.fr

5 Reference Center MARHEA, Department of Pediatric Nephrology, Imagine Institute, INSERM U1163, Necker Hospital, Université de Paris, AP-HP, F-75015 Paris, France; Margaux.boistault@aphp.fr (M.B.); olivia.boyer@aphp.fr (O.B.)

6 Department of Pediatric Immunology, Hematology and Rheumatology, INSERM U1163, Imagine Institute, Necker Hospital, Université de Paris, AP-HP, F-75015 Paris, France; brigitte.bader-meunier@aphp.fr

check for
updates

Citation: Zahr, N.; Urien, S.; Funck-Brentano, C.; Vantomme, H.; Garcelon, N.; Melki, I.; Boistault, M.; Boyer, O.; Bader-Meunier, B.

Evaluation of Hydroxychloroquine Blood Concentrations and Effects in Childhood-Onset Systemic Lupus Erythematosus. Pharmaceuticals 2021, 14, 273. https://doi.org/ $10.3390 /$ ph14030273

Academic Editor: Félix Carvalho

Received: 15 February 2021

Accepted: 12 March 2021

Published: 17 March 2021

Publisher's Note: MDPI stays neutral with regard to jurisdictional claims in published maps and institutional affiliations.

Copyright: (c) 2021 by the authors. Licensee MDPI, Basel, Switzerland. This article is an open access article distributed under the terms and conditions of the Creative Commons Attribution (CC BY) license (https:// creativecommons.org/licenses/by/ $4.0 /)$.
* Correspondence: noel.zahr@aphp.fr; Tel.: +33-142-162-022

+ These authors contributed equally to this work.

Abstract: Background: Hydroxychloroquine (HCQ) is an antimalarial agent given to patients with systemic lupus erythematosus (SLE) as first-line therapy. It alleviates childhood-onset systemic lupus erythematosus cSLE skin and musculoskeletal disease, decreasing disease activity and flares. HCQ concentration-effect relationships in children remains unknown. This study aimed to investigate the pharmacokinetics of HCQ and possible concentration-effect relationships. Methods: HCQ blood concentrations and effects were obtained during clinical follow-up on different occasions. cSLE flares were defined using the SLE Disease Activity Index (SLEDAI); flare was denoted by a SLEDAI score $>6$. Blood concentration was measured using high-performance liquid chromatography with fluorometric detection. Statistical analysis was performed using a nonlinear mixed-effect approach with the Monolix software. Results: A total of 168 blood samples were obtained from 55 pediatric patients. HCQ apparent blood clearance $(\mathrm{CL} / \mathrm{F})$ was dependent on patients' bodyweight and platelet count. Patients with active cSLE had a lower mean blood HCQ concentration compared with inactive cSLE patients ( $536 \pm 294$ vs. $\left.758 \pm 490 \mathrm{ng} / \mathrm{mL}, p=5 \times 10^{-6}\right)$. Among patients with HCQ blood concentration $\geq 750 \mathrm{ng} / \mathrm{mL}, 87.6 \%$ had inactive cSLE. Moreover, HCQ blood concentration was a significant predictor of disease status. Conclusion: We developed the first HCQ blood concentrationeffect relationship for cSLE associated with active or non-active disease status. A prospective randomized study is necessary to confirm these results.

Keywords: hydroxychloroquine; systemic lupus erythematosus; pharmacokinetics; pharmacodynamics

\section{Introduction}

Childhood-onset systemic lupus erythematosus (cSLE) is a chronic systemic autoimmune disease with incidence of 0.3-0.9 per 100,000 children-years. Compared with adults with SLE, children experience a greater disease activity and higher rates of renal disease [1-3]. In adults with SLE, hydroxychloroquine (HCQ) significantly decreases disease 
activity, with fewer relapses and improved damage-free survival [4,5]. Moreover, nonadherence to HCQ has been identified as a major cause of lupus flares [6-8]. Recently, it was recommended that all children with lupus should routinely be treated with HCQ [9].

After oral administration, HCQ is well absorbed with an absolute bioavailability of $79 \%$. Peak blood concentrations are reached within 3 to 4 hours. HCQ is characterized by a large apparent volume of distribution ( $>2000 \mathrm{~L})$ due to poor plasma protein binding $(\sim 50 \%)$ and high tissue binding, including blood cells [10]. The HCQ metabolic pathways involve cytochrome-P450s CYP2C8 and CYP3A and, to a lesser extent, CYP2D6 [10-12].

However, blood concentrations of HCQ show a high interindividual variability for the same administered dose. This variability has been observed in compliant adult patients with rheumatoid arthritis (RA), SLE, and COVID-19 [13-17]. A meta-analysis demonstrated the association between low HCQ levels and reported nonadherence and a threshold of $750 \mathrm{ng} / \mathrm{mL}$ blood HCQ concentration has been proposed as a target in the treatment of adults with SLE [16]. According to Chasset et al. when blood HCQ concentrations were higher than $750 \mathrm{ng} / \mathrm{mL}$, a significant improvement of skin lesions was observed in patients with refractory cutaneous lupus erythematosus [18]. The relationship between blood concentrations of HCQ and clinical efficacy has also been demonstrated in RA [13,14]. However, no data are available in pediatric SLE. In this retrospective study, we aimed to investigate the relationship between HCQ blood concentration and SLE activity in order to optimize HCQ treatment of children with SLE.

\section{Results}

A total of 168 blood samples and 623 SLEDAI scores were obtained from 55 children, of which $94 \%$ were girls. Among the girls, $72 \%$ experienced menarche. There were 15 and 6 concentrations below the limit of quantification (BLQ) and detected as outliers, respectively, that were removed from the final analysis for nonadherence. Most subjects took $400 \mathrm{mg}$ HCQ once a day (Table 1). The mean duration of HCQ treatment for patients without retinal toxicity was $3.1 \pm 2.3$ years. There were 56 and 1 observations corresponding to stage 2 and stage 3 chronic kidney disease (Schwartz $<90$ and $60 \mathrm{~mL} / \mathrm{min} / 1.73 \mathrm{~m}^{2}$ ), respectively. There were 135 SLEDAI scores above 6 units $(21.7 \%)$. The detailed patient characteristics are summarized in Table 1.

\subsection{Data Analysis}

Large interindividual variations in blood HCQ concentrations were observed. Blood clearance was significantly related to bodyweight (WT exponent was then fixed to 0.75 according to allometric scaling) and platelet count (PLAT). FFM was not a better descriptor for $\mathrm{CL} / \mathrm{F}$ than total bodyweight. There was no significant effect of the before or after menarche status on CL/F. For these covariates, median physiologic values for an adult patient were used in the equation, $70 \mathrm{~kg}$ and $250 \times 10^{9} / \mathrm{L}$. The final covariate submodel for $\mathrm{CL} / \mathrm{F}$ was then

$$
\mathrm{CL} / \mathrm{F}(\mathrm{L} / \mathrm{h})=19.6 \times(\mathrm{WT} / 70)^{0.75} \times(\mathrm{PLAT} / 250,000)^{-0.648} .
$$

Parameter estimates are summarized in Table 2. The goodness-of-fit plots for the final model are shown in Figure 1. 
Table 1. Demographic, biological, and disease characteristics of the 55 patients.

\begin{tabular}{|c|c|c|c|}
\hline Covariate & Mean \pm Standard Deviation & Min & $\operatorname{Max}$ \\
\hline Age, years & $15 \pm 2$ & 5.5 & 18 \\
\hline Weight, kg & $51 \pm 18$ & 18.8 & 120 \\
\hline $\operatorname{Sex},(\mathrm{F})(n / N)$ & $151 / 168$ & NA & NA \\
\hline Schwartz, $\mathrm{mL} / \mathrm{min} / 1.73 \mathrm{~m}^{2}$ & $116 \pm 26$ & 34 & 201 \\
\hline Creatinine, $\mu \mathrm{mol} / \mathrm{L}$ & $50 \pm 14$ & 25 & 163 \\
\hline Albumin, g/L & $38 \pm 6$ & 11 & 68 \\
\hline $\mathrm{Hb}, \mathrm{g} / \mathrm{dL}$ & $12 \pm 1.5$ & 7 & 17.7 \\
\hline Platelet, $10^{9} / \mathrm{L}$ & $267 \pm 75$ & 76 & 674 \\
\hline Proteinuria, $\mathrm{g} / \mathrm{L}$ & $1.2 \pm 1.5$ & 0 & 7.5 \\
\hline White blood cells, $10^{9} / \mathrm{L}$ & $5.28 \pm 2.1$ & 2 & 10.8 \\
\hline $\mathrm{C} 3(\mathrm{mg} / \mathrm{L})$ & $887 \pm 253$ & 126 & 1460 \\
\hline SLEDAI score & $4.4 \pm 3.9$ & 0 & 25 \\
\hline Dose HCQ, mg/kg/day & $5.7 \pm 2.1$ & 2 & 15.7 \\
\hline \multicolumn{4}{|l|}{ Comedications: } \\
\hline Corticosteroids $(n / N)$ & $136 / 168$ & NA & NA \\
\hline Immunosuppressant $(n / N)$ & $104 / 168$ & NA & NA \\
\hline Concentration HCQ, ng/mL & $665 \pm 433$ & 100 & 2509 \\
\hline Sampling time, day & $1100 \pm 830$ & 10 & 3674 \\
\hline
\end{tabular}

NA: not applicable; Hb: hemoglobin; SLEDAI: Systemic Lupus Erythematosus Disease Activity Index; HCQ: hydroxychloroquine; $\mathrm{n}$ : number of cases; $\mathrm{N}$ : number of observations; $\mathrm{C} 3$ : complement protein. All data were collected at the time of HCQ sampling.

Table 2. Population parameter estimates of HCQ kinetics and effects on disease status, active or non-active disease (SLEDAI score $>6$ or not) in 55 children with systemic lupus disease.

\begin{tabular}{|c|c|c|}
\hline Fixed Effects Parameters & Estimate & RSE (\%) \\
\hline Blood Clearance ${ }^{\#}, \mathrm{CL} / \mathrm{F}_{\mathrm{POP}}(\mathrm{L} / \mathrm{h}$ standardized to $70 \mathrm{~kg})$ & 19.6 & 5.35 \\
\hline Weight effect on CL/F, $(\mathrm{WT} / 70)^{\mathrm{WT}}$ & $0.75 \rightarrow$ fixed & NA \\
\hline Platelet effect on CL/F, (Platelet/250,000) ${ }^{\text {PLAT }}$ & -0.648 & 25 \\
\hline \multicolumn{3}{|l|}{ Effect on disease, SLEDAI score > 6 units $\#$} \\
\hline intercept & 5.55 & 30 \\
\hline $\mathrm{b}_{\mathrm{HCQ}}$, slope for $\log _{10}$ (HCQ concentration) effect & -2.41 & 24 \\
\hline \multicolumn{3}{|l|}{ Variabilities } \\
\hline$\omega_{\mathrm{CL}}$ & 0.263 & 22 \\
\hline$\sigma$, proportional & 0.385 & 8 \\
\hline$\omega_{\text {intercept }}$ & 1.88 & 18 \\
\hline
\end{tabular}



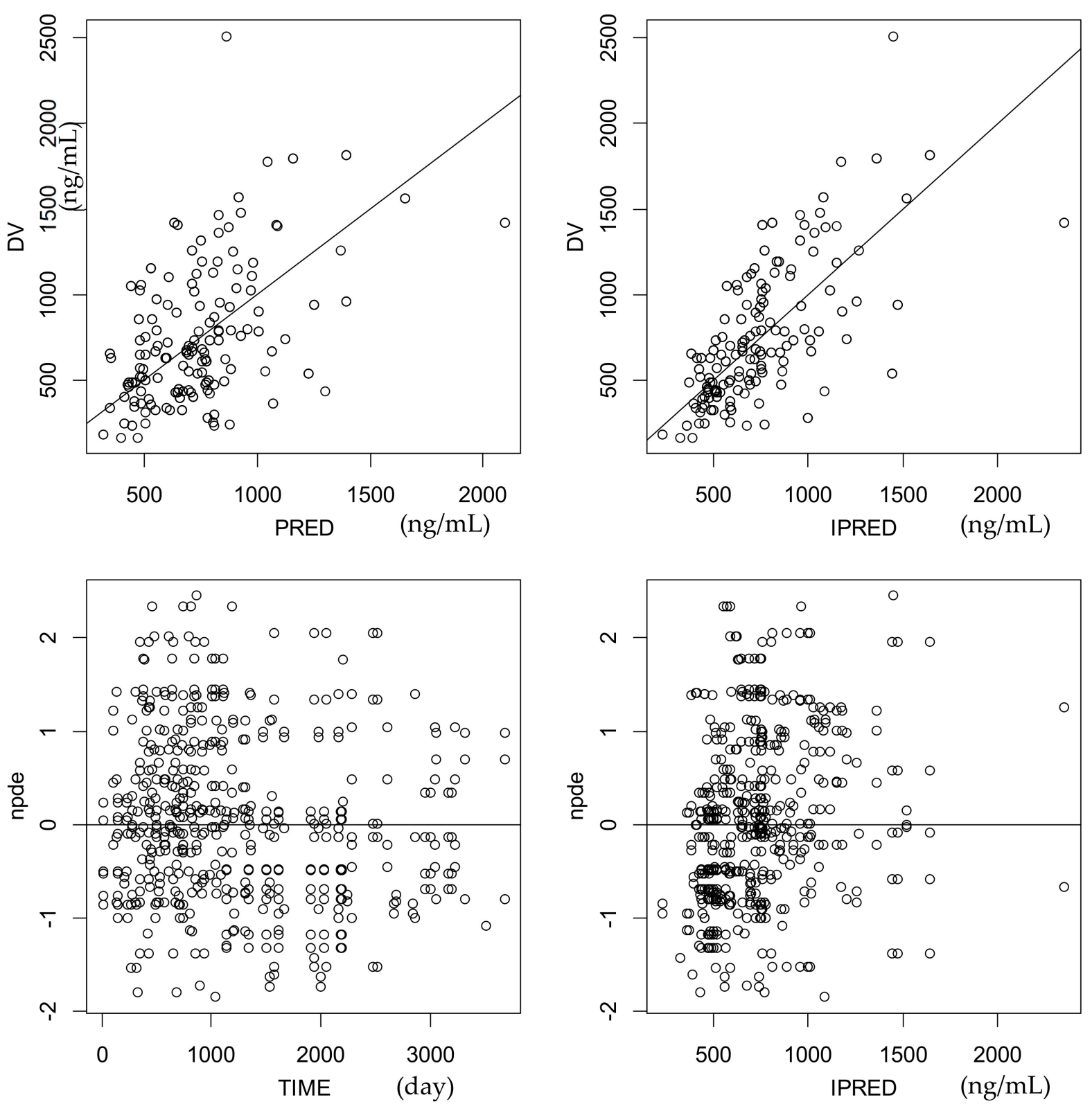

Figure 1. Goodness-of-fit plots showing the observed HCQ concentrations (DV) versus predicted (PRED) and individual predicted concentrations (IPRED) and normalized prediction distribution errors (npde) versus time and IPRED for the final model.

\subsection{Association between HCQ Treatment and SLEDAI Score}

The mean SLEDAI score was $4.2 \pm 3.9$. Children with active cSLE had a lower mean $\mathrm{C}_{\mathrm{HCQ}}$ than patients with inactive cSLE (536 \pm 294 vs. $758 \pm 490 \mathrm{ng} / \mathrm{mL}, p=5 \times 10^{-6}$ ). When $\mathrm{C}_{\mathrm{HCQ}}$ was $\geq 750 \mathrm{ng} / \mathrm{mL}, 87.6 \%$ of patients had inactive cSLE. When $\mathrm{C}_{\mathrm{HCQ}}$ was $<750$ or $>750 \mathrm{ng} / \mathrm{mL}$, an immunosuppressive treatment was present in $66.4 \%$ and $52.8 \%$ of patients, respectively $(p=0.0013)$. Response to HCQ treatment was significantly related to $\mathrm{C}_{\mathrm{HCQ}}$. The treatment duration was not retained since the addition of this effect increased the BIC. The final logit relationship was

$$
\operatorname{logit}\left(\mathrm{P}\{\mathrm{SLEDAI}>6\}=5.55-2.41 \times \log _{10}\left(\mathrm{C}_{\mathrm{HCQ}}\right)\right.
$$

showing that $\mathrm{C}_{\mathrm{HCQ}}$ decreased the probability of active disease status. Figure 2 shows the decrease of the percentage of active disease cases versus $C_{H C Q}$. Figure 3 shows the SLEDAI scores versus $\mathrm{C}_{\mathrm{HCQ}}$. Note that the model prediction curve is included in the confidence 
intervals (CIs) of observed percentages. The odds ratio for the HCQ effect is then 0.09 (95\% confidence interval $0.05-0.16)$, which indicates that one unit increase in one $\log 10\left(\mathrm{C}_{\mathrm{HCQ}}\right)$ unit results in a $9 \%$ decrease in the probability of active disease status.

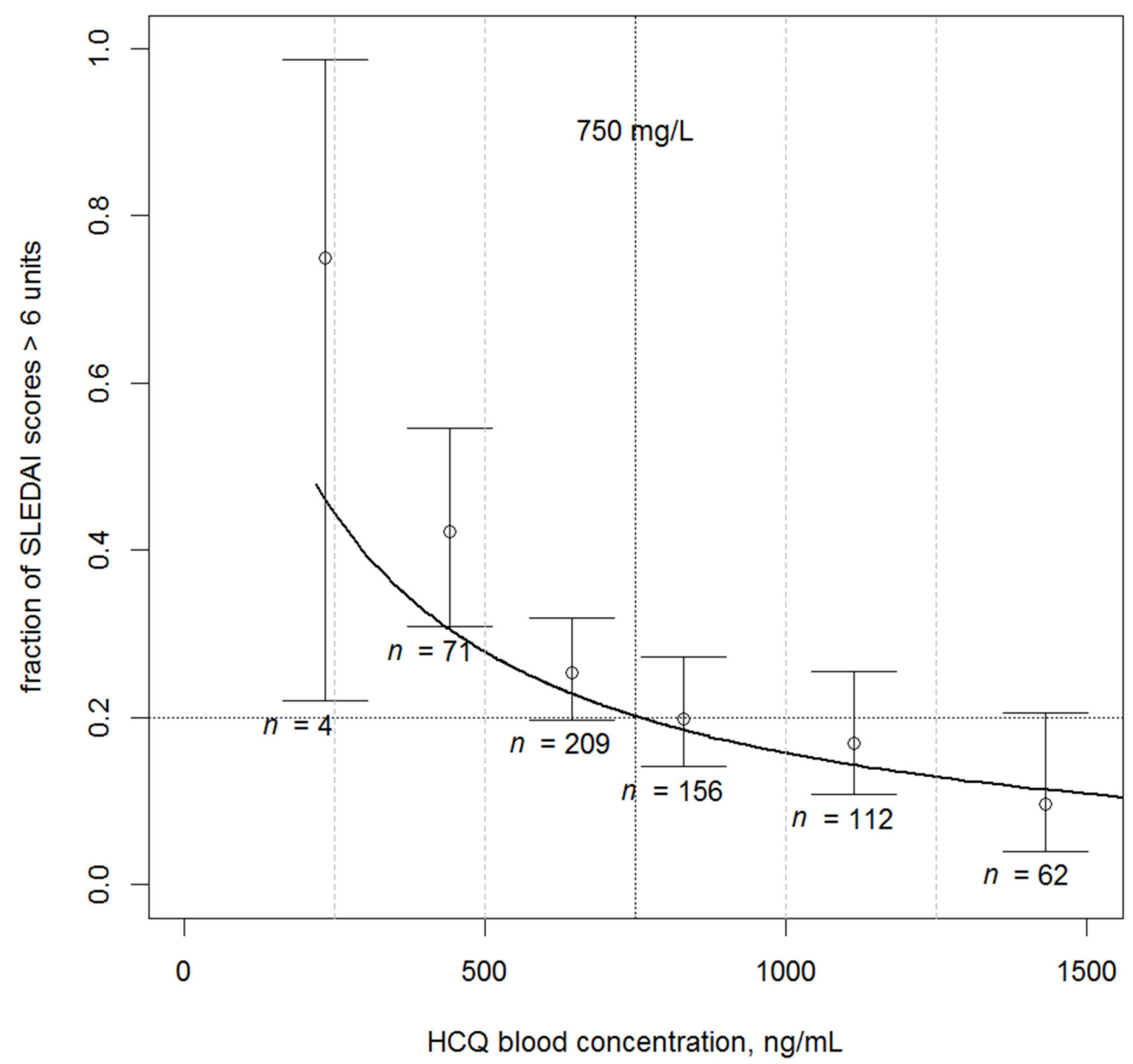

Figure 2. Observed and model-predicted percentages of scores $>6$ units as a function of blood HCQ concentrations. Note that the $750 \mathrm{ng} / \mathrm{mL}$ threshold is associated with a 20\% risk of active disease status. Open circles and segments, observed percentages with their $95 \%$ confidence intervals; black curve, median prediction; vertical dashed lines denote the concentration intervals for percentage estimations. 


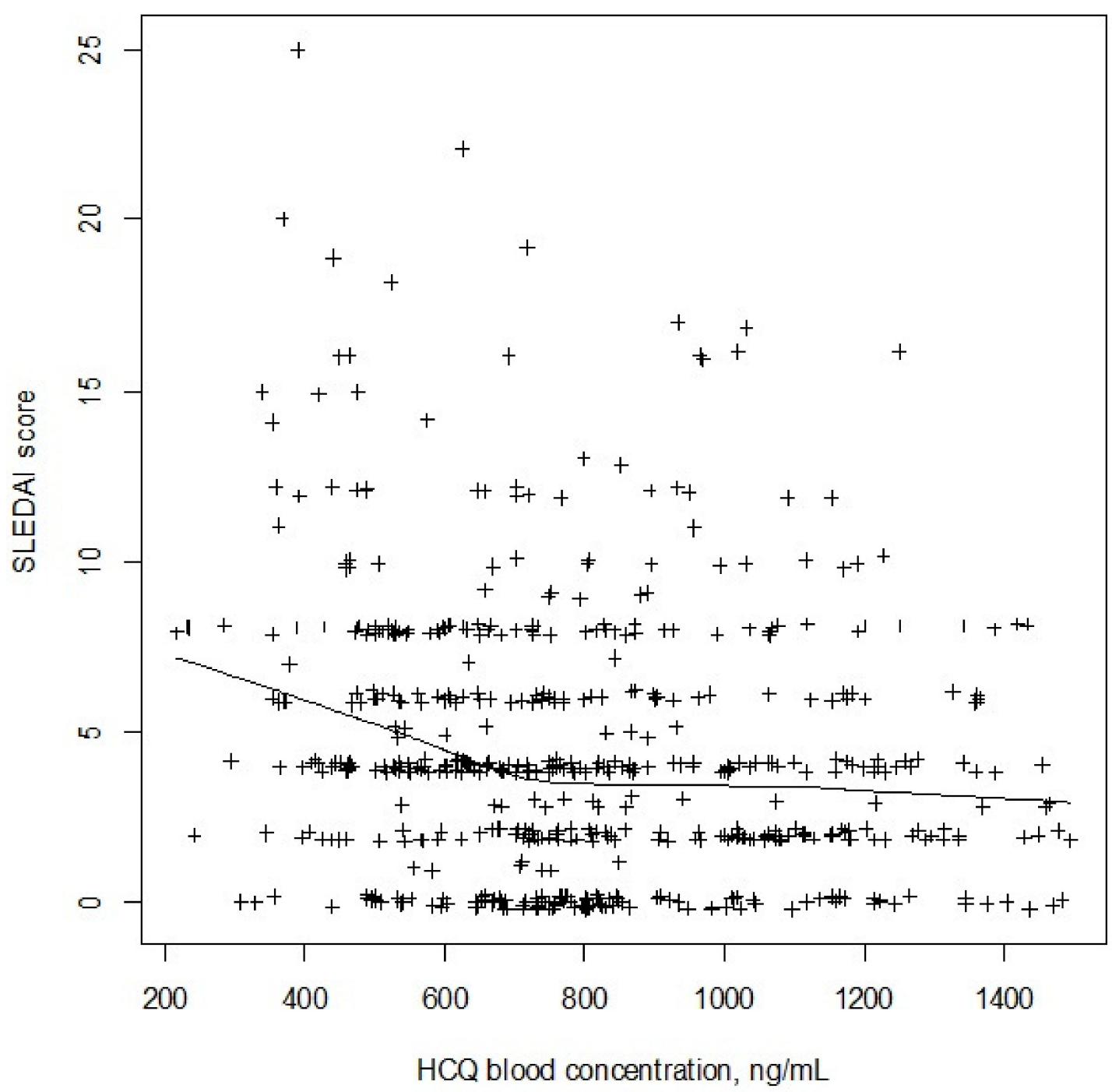

Figure 3. SLEDAI scores as a function of blood HCQ concentrations. The black curve is drawn after a spline function and shows the trend.

\subsection{Dosage Recommendations}

The dosing schedule to target blood HCQ concentrations $>750 \mathrm{ng} / \mathrm{mL}$ (therapeutic threshold) was derived from simulations of the final model. As summarized in Table 3, four weight bands from 15 to $70 \mathrm{~kg}$ were retained. This dosing schedule showed that approximately $45 \%$ were at risk of underdosage. Figure 4 depicts the mean concentrationtime courses for these 4 weight bands, which reach the same plateau.

Table 3. Hydroxychloroquine dosage recommendation in $\mathrm{mg} / \mathrm{kg} /$ day to achieve blood concentrations greater than $750 \mathrm{ng} / \mathrm{mL}$ (Prob: probability; C: blood HCQ concentration (ng/mL).

\begin{tabular}{ccc}
\hline Bodyweight Band kg & Dosage $\mathbf{~ m g} / \mathbf{k g} /$ Day & Prob $(\mathbf{C}>750) \mathbf{n g} / \mathbf{m L}$ \\
\hline $15-21.9$ & 9 & 53.4 \\
\hline $22-34.9$ & 8 & 55 \\
\hline $35-60.9$ & 7 & 54.4 \\
\hline $61-71$ & 6.5 & 52.7 \\
\hline
\end{tabular}




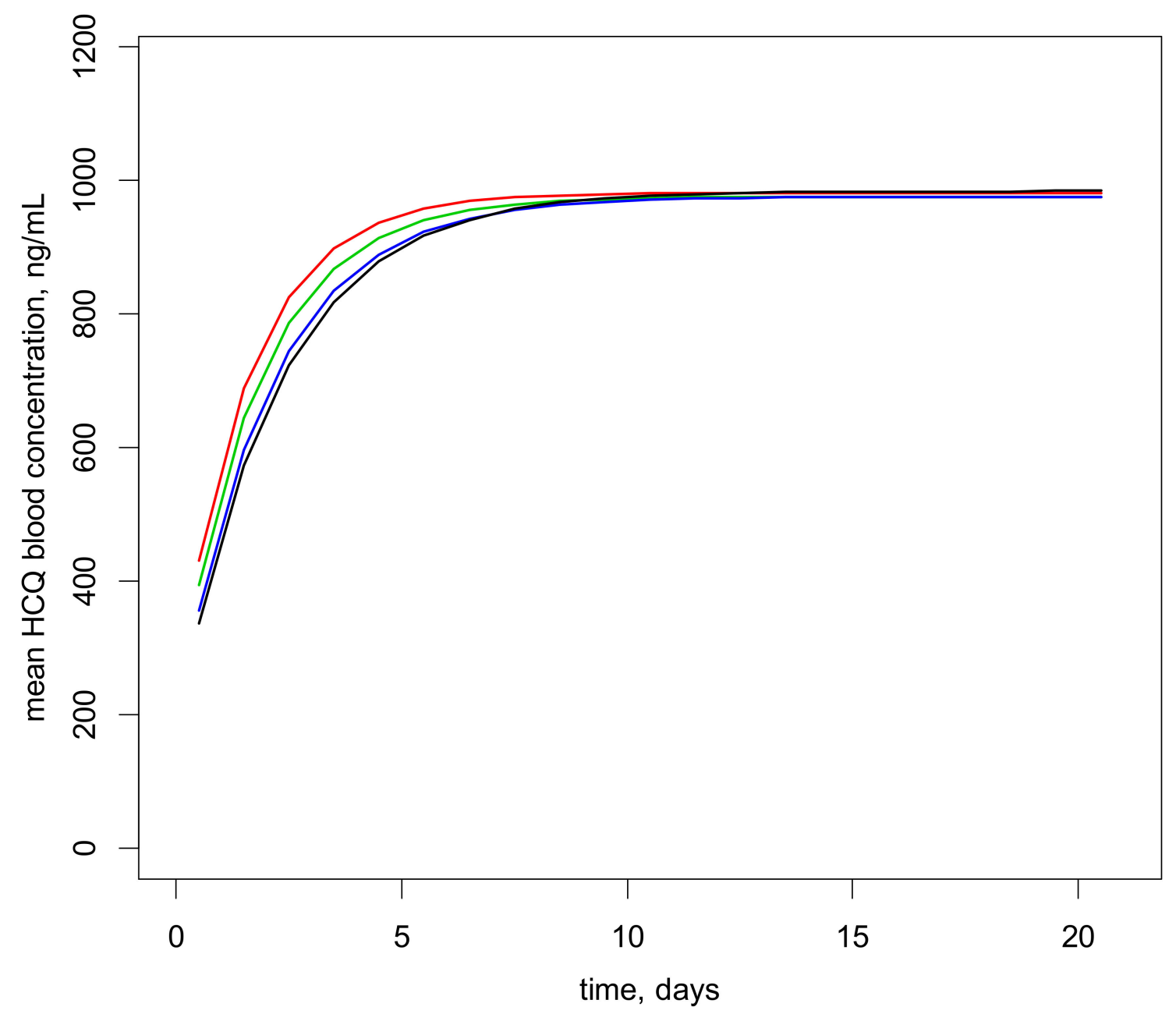

Figure 4. Mean blood HCQ concentration-time courses obtained using the dosing schedule from Table 3. Patient bodyweights are set to the mean of each weight band, 18 (red), 28 (green), 47.5 (blue), and 66 (black) kg. The curves connect the mean concentrations computed at each dose interval.

\subsection{Blood HCQ Concentrations and Retinal Toxicity}

Retinal toxicity was observed in three patients. These patients started treatment with HCQ at the age of $14.8,15.9$, and 8.8 years. The first patient received $200 \mathrm{mg}$ of HCQ for 2.6 years then $400 \mathrm{mg}$ for 1.2 years. For the other two patients, the dose was 400 and $200 \mathrm{mg}$ for 0.8 and 8.9 years, respectively. Retinal toxicity was observed in 3 patients after 2.3, 0.8 and 8.2 years of treatment with HCQ, respectively. Their blood HCQ concentrations were $<100,199$, and $459 \mathrm{ng} / \mathrm{mL}$.

\section{Discussion}

This retrospective study shows that monitoring blood $\mathrm{C}_{\mathrm{HCQ}}$ in cSLE might be useful to understand treatment failures and optimize treatment efficacy. Targeting HCQ levels $\geq 750 \mathrm{ng} / \mathrm{mL}$ appears to be a reasonable therapeutic threshold (80\% of SLEDAI scores $<6$ ) similarly to the recommended target in adult patients with SLE. Several studies have shown a correlation between $\mathrm{C}_{\mathrm{HCQ}}$ and efficacy in SLE and rheumatoid arthritis in adults [14-16]. In this study, we demonstrated that bodyweight and platelet count significantly influenced HCQ blood clearance. The effect of weight was expected, since in this pediatric group, the weight ranged from 19 to $120 \mathrm{~kg}$, and it is well established that HCQ CL is a function of WT0.75 [19]. Obesity did not significantly influence CL/F. However, with only 3 of 55 patients having a BMI $>30 \mathrm{~kg} / \mathrm{m}^{2}$, the study lacked power to assess the influence of bodyweight on HCQ pharmacokinetics. The expression and activity of drug 
metabolism is affected by variety of physiological factors, (e.g., sex, menstrual cycle, age). Moreover, it has been demonstrated that estrogen downregulates CYP3A4 expression [20]. In our study, menarche had no significant influence on CL/F of HCQ. Platelet count also showed wide variations, ranging from 76 to $674 \times 10^{9} / \mathrm{L}$ and the decrease of CL as a function of platelet count is likely due to HCQ binding to platelets, retaining HCQ in the bloodstream and thus limiting the distribution of HCQ to eliminating organs. High body mass index and low platelet count were significantly associated with low blood HCQ concentrations [11]. The CL/F estimation, $19.8 \mathrm{~L} / \mathrm{h} / 70 \mathrm{~kg}$, which is very close to the value of $19 \mathrm{~L} / \mathrm{h}$ per $69 \mathrm{~kg}$ or reported by Carmichael et al. [21] obtained using a similar method and $18.6 \mathrm{~L} / \mathrm{h}$ per $53 \mathrm{~kg}$ reported by Morita et al. [12].

Moreover, blood HCQ concentrations were associated with disease activity, i.e., the higher the concentration of HCQ, the lower the percentage of active disease status. A similar relationship between low blood HCQ concentration and higher SLE activity was demonstrated in adult SLE [11]. Blood HCQ concentration was significantly higher in patients with inactive cSLE $(758 \mathrm{ng} / \mathrm{mL}$; range, 100-2509) than in patients with active cSLE (536 ng/mL; range, 50-1408) ( $p=0.005)$.

Dosing recommendations for pediatric patients according to bodyweight could be determined. Considering a therapeutic threshold $\geq 750 \mathrm{ng} / \mathrm{mL}$, a conservative dosing strategy was established in $\mathrm{mg} / \mathrm{kg} /$ day for 4 bodyweight bands. Because of the high between-subject and residual variabilities observed with this orally administered drug, only $45-50 \%$ of the expected concentrations were in the window. Therapeutic drug monitoring should be applied to optimize HCQ dosage following 10-15 days of treatment. Furthermore, some of these dosage recommendations are higher than $6.5 \mathrm{mg} / \mathrm{kg} /$ day to reach the threshold of $750 \mathrm{ng} / \mathrm{mL}$ during the first month of treatment, and the tablet $(200 \mathrm{mg})$ is not suitable for children weighing less than $25 \mathrm{~kg}$. Therefore, a prospective analysis is necessary to confirm these results.

Limitations of this retrospective study: (i) compliance with therapy was mainly achieved using therapeutic drug monitoring; (ii) due to a relatively small sample size, no significant relationship could be found between blood HCQ concentration and retinal toxicity (in the three children with retinopathy, blood HCQ concentrations were $<100,199$, and $459 \mathrm{ng} / \mathrm{mL}$ after 2.3, 0.8 , and 8.2 years of treatment with HCQ, respectively).

\section{Materials and Methods}

\subsection{Patients and Drug Assay}

In the present study, we performed a retrospective analysis of the requests of HCQ dosage collected in patients followed up in two French Reference National centers for pediatric rare autoimmune diseases between October 2009 and November 2018. Patients were enrolled if they fulfilled all the following criteria: disease that met the American College of Rheumatology classification criteria for SLE and diagnosed before 16 years of age; treatment with oral hydroxychloroquine sulfate (Plaquenil, Sanofi-Winthrop, Paris, France). The Schwartz equation was used for glomerular filtration rate (GFR) estimation. SLE status was assessed using the SLE Disease Activity Index (SLEDAI) at time of each HCQ dosage. Blood samplings were obtained during clinics, but the exact time of drug administration relative to blood sampling was not recorded. HCQ assay was routinely performed in the same pharmacological laboratory in order to assess patient compliance. All patients underwent an annual ophthalmological examination, comprising at least fundus examination, 10.2 automated visual field, and SD-OCT optical coherence tomography. Patients ${ }^{\prime}$ medical records were retrospectively reviewed for demographic, clinical, and biological characteristics and ophthalmological examination. Whole-blood HCQ concentrations were assayed by U-HPLC with fluorometric detection as previously described [22]. The study was performed in accordance with French regulations and approval was obtained from Necker Hospital Ethics Council (Ref 2018-NZ 7). 


\subsection{Data Analysis}

According to pharmacokinetic principles, mean $\mathrm{C}_{\mathrm{HCQ}}$ is related to apparent $\mathrm{HCQ}$ blood clearance ( $\mathrm{CL} / \mathrm{F}$, where $\mathrm{F}$ is the unknown bioavailability) via the equation

$$
\mathrm{C}_{\mathrm{HCQ}} \times(\mathrm{CL} / \mathrm{F})=\text { Rate }
$$

where Rate denotes the dose rate (Rate $=$ dose $/$ Interdose Interval). $\mathrm{CL} / \mathrm{F}$ was adjusted to the bodyweight (WT) according to the allometric rule

$$
\mathrm{CL} / \mathrm{F}=\mathrm{CL} / \mathrm{F}_{\mathrm{POP}}{ }^{*}(\mathrm{WT} / 70)^{0.75}
$$

The subscript POP denotes the average population value standardized for an adult weighing $70 \mathrm{~kg}$.

Parameter estimation was performed using the non-linear mixed-effect modeling software Monolix (version 2019R2) that is able to estimate both between-subject (BSV or $\omega$ ) and residual variabilities $(\sigma)$. BSV was ascribed to an exponential model and $\sigma$ to a proportional model. The observations below the limit of quantification (BLQ) were removed from the analysis because they were thought to indicate nonadherence. Observations more than 3 times or less than $1 / 3$ of individual predicted concentrations were considered as outliers and removed from the final analysis. Individual characteristics that may influence CL/F were checked for bodyweight (WT), free-fat mass (FFM) REF [23], age, sex, renal function using the Schwartz index, platelet count, and serum albumin. For young females, the effect of menarche (before, after) was also investigated. The effect of quantitative covariates was modeled as shown in Equation (1). The Bayesian information criterion (BIC) was used to test for covariate effects. The goodness-of-fit of each model was evaluated by visual inspection of the observed versus population and individual predicted concentration, plus residual (npde, normalized prediction distribution error) scatter plots.

Given the zero inflation in the SLEDAI data, a linear regression of SLEDAI versus $\mathrm{C}_{\mathrm{HCQ}}$ was not appropriate since the distribution deviated from normality. The SLEDAI scores were then converted to binary scores, inactive or active disease status, i.e., SLEDAI in 0 to 6 units or SLEDAI $>6$ units [15]. The logistic regression expression was

$$
\operatorname{Logit}\{\mathrm{P}(\mathrm{SLEDAI}>6)\}=\mathrm{b}_{0}+\mathrm{b}_{\mathrm{i}} \times \log \left(\mathrm{V}_{\mathrm{i}}\right)
$$

where the $b_{i}$ terms denote the slopes quantifying the effects of explicative variables $V_{i}$ denoted by subscripts $i$. For $\mathrm{C}_{\mathrm{HCQ}}$, the values were set to the individual predictions that allowed to include all SLEDAI scores (using Monolix).

Given the final results, 500 simulations of HCQ concentrations at steady state were performed for patient bodyweights ranging from 15 to $70 \mathrm{~kg}$. The probabilities to observe concentrations greater than $750 \mathrm{ng} / \mathrm{mL}$ (risk of inefficacy) were then estimated.

\section{Conclusions}

Our study shows that blood concentrations of hydroxychloroquine are associated with disease activity in children with systemic lupus erythematosus. It suggests that blood hydroxychloroquine concentrations $\geq 750 \mathrm{ng} / \mathrm{mL}$ may be a potential therapeutic target concentration in this population.

Author Contributions: Conceptualization, N.Z. and B.B.-M.; methodology, N.Z. and S.U.; validation, N.Z., S.U., O.B., C.F.-B. and B.B.-M.; formal analysis, S.U.; investigation, H.V., N.G., I.M. and M.B.; writing-original draft preparation, N.Z. and S.U.; writing-review and editing, N.Z., S.U., C.F.-B., O.B. and B.B.-M.; supervision, N.Z., O.B., C.F.-B. and B.B.-M. All authors have read and agreed to the published version of the manuscript.

Funding: This research received no external funding.

Institutional Review Board Statement: The study was performed in accordance with French regulations and approval was obtained from Necker Hospital Ethics Council (Ref 2018-NZ 7). 
Informed Consent Statement: French regulations on non-interventional observational studies do not require patient consent when analyzing data obtained from routine care. Approval for data collection was obtained from the Commission Nationale de $l^{\prime}$ Informatique et des Libertés (n¹491960v0).

Data Availability Statement: The data support the findings of this study are available on request from the corresponding author upon reasonable request.

Acknowledgments: The authors would like to thank Albert Faye and Julien Hogan from Robert Debré hospital for their implication in the medical follow-up of two patients.

Conflicts of Interest: The authors declare no conflict of interest.

\section{References}

1. Pineles, D.; Valente, A.; Warren, B.; Peterson, M.G.; Lehman, T.J.; Moorthy, L.N. Worldwide incidence and prevalence of pediatric onset systemic lupus erythematosus. Lupus 2011, 20, 1187-1192. [CrossRef] [PubMed]

2. Hersh, A.O.; von Scheven, E.; Yazdany, J.; Panopalis, P.; Trupin, L.; Julian, L.; Katz, P.; Criswell, L.A.; Yelin, E. Differences in long-term disease activity and treatment of adult patients with childhood- and adult-onset systemic lupus erythematosus. Arthritis Rheum. 2009, 61, 13-20. [CrossRef]

3. Brunner, H.I.; Gladman, D.D.; Ibanez, D.; Urowitz, M.D.; Silverman, E.D. Difference in disease features between childhood-onset and adult-onset systemic lupus erythematosus. Arthritis Rheum. 2008, 58, 556-562. [CrossRef] [PubMed]

4. Fanouriakis, A.; Kostopoulou, M.; Alunno, A.; Aringer, M.; Bajema, I.; Boletis, J.N.; Cervera, R.; Doria, A.; Gordon, C.; Govoni, M.; et al. 2019 update of the EULAR recommendations for the management of systemic lupus erythematosus. Ann. Rheum. Dis. 2019, 78, 736-745. [CrossRef] [PubMed]

5. Canadian Hydroxychloroquine Study Group. A randomized study of the effect of withdrawing hydroxychloroquine sulfate in systemic lupus erythematosus. N. Engl. J. Med. 1991, 324, 150-154. [CrossRef] [PubMed]

6. Van Vollenhoven, R.F.; Mosca, M.; Bertsias, G.; Isenberg, D.; Kuhn, A.; Lerstrom, K.; Aringer, M.; Bootsma, H.; Boumpas, D.; Bruce, I.N.; et al. Treat-to-target in systemic lupus erythematosus: Recommendations from an international task force. Ann. Rheum. Dis. 2014, 73, 958-967. [CrossRef] [PubMed]

7. Koneru, S.; Kocharla, L.; Higgins, G.C.; Ware, A.; Passo, M.H.; Farhey, Y.D.; Mongey, A.B.; Graham, T.B.; Houk, J.L.; Brunner, H.I. Adherence to medications in systemic lupus erythematosus. J. Clin. Rheumatol. 2008, 14, 195-201. [CrossRef] [PubMed]

8. Rojas-Serrano, J.; Cardiel, M.H. Lupus patients in an emergency unit. Causes of consultation, hospitalization and outcome. A cohort study. Lupus 2000, 9, 601-606. [CrossRef] [PubMed]

9. Groot, N.; de Graeff, N.; Avcin, T.; Bader-Meunier, B.; Brogan, P.; Dolezalova, P.; Feldman, B.; Kone-Paut, I.; Lahdenne, P.; Marks, S.D.; et al. European evidence-based recommendations for diagnosis and treatment of childhood-onset systemic lupus erythematosus: The SHARE initiative. Ann. Rheum. Dis. 2017, 76, 1788-1796. [CrossRef]

10. Tett, S.E.; Cutler, D.J.; Day, R.O.; Brown, K.F. A dose-ranging study of the pharmacokinetics of hydroxy-chloroquine following intravenous administration to healthy volunteers. Br. J. Clin. Pharmacol. 1988, 26, 303-313. [CrossRef]

11. Jallouli, M.; Galicier, L.; Zahr, N.; Aumaitre, O.; Frances, C.; Le Guern, V.; Liote, F.; Smail, A.; Limal, N.; Perard, L.; et al. Determinants of hydroxychloroquine blood concentration variations in systemic lupus erythematosus. Arthritis Rheumatol. 2015, 67, 2176-2184. [CrossRef] [PubMed]

12. Morita, S.; Takahashi, T.; Yoshida, Y.; Yokota, N. Population pharmacokinetics of hydroxychloroquine in Japanese patients with cutaneous or systemic lupus erythematosus. Ther. Drug Monit. 2016, 38, 259-267. [CrossRef] [PubMed]

13. Tett, S.E.; Cutler, D.J.; Beck, C.; Day, R.O. Concentration-effect relationship of hydroxychloroquine in patients with rheumatoid arthritis-A prospective, dose ranging study. J. Rheumatol. 2000, 27, 1656-1660. [PubMed]

14. Munster, T.; Gibbs, J.P.; Shen, D.; Baethge, B.A.; Botstein, G.R.; Caldwell, J.; Dietz, F.; Ettlinger, R.; Golden, H.E.; Lindsley, H.; et al. Hydroxychloroquine concentration-response relationships in patients with rheumatoid arthritis. Arthritis Rheum. 2002, 46, 1460-1469. [CrossRef] [PubMed]

15. Costedoat-Chalumeau, N.; Amoura, Z.; Hulot, J.S.; Hammoud, H.A.; Aymard, G.; Cacoub, P.; Frances, C.; Wechsler, B.; Huong Du, L.T.; Ghillani, P.; et al. Low blood concentration of hydroxychloroquine is a marker for and predictor of disease exacerbations in patients with systemic lupus erythematosus. Arthritis Rheum. 2006, 54, 3284-3290. [CrossRef]

16. Garg, S.; Unnithan, R.; Hansen, K.E.; Costedoat-Chalumeau, N.; Bartels, C.M. The Clinical significance of monitoring hydroxychloroquine levels in patients with systemic lupus erythematosus: A systematic review and meta-analysis. Arthritis Care Res. 2020. [CrossRef] [PubMed]

17. Noël, Z.; Saik, U.; Benoit, L.; Valérie, P.; Olivier, P.; Alexandre, B.; Julien, M.; Estelle, G.; Guillaume, H.; Alain, C.; et al. Pharmacokinetics and pharmacodynamics of hydroxychloroquine in hospitalized patients with COVID-19. Therapies 2021. [CrossRef]

18. Chasset, F.; Arnaud, L.; Costedoat-Chalumeau, N.; Zahr, N.; Bessis, D.; Frances, C. The effect of increasing the dose of hydroxychloroquine (HCQ) in patients with refractory cutaneous lupus erythematosus (CLE): An open-label prospective pilot study. J. Am. Acad. Dermatol. 2016, 74, 693-699. [CrossRef] [PubMed] 
19. Anderson, B.J.; Holford, N.H. Mechanism-based concepts of size and maturity in pharmacokinetics. Annu. Rev. Pharmacol. Toxicol. 2008, 48, 303-332. [CrossRef]

20. Monostory, K.; Dvorak, Z. Steroid regulation of drug-metabolizing cytochromes P450. Curr. Drug Metab. 2011, 12, 154-172. [CrossRef]

21. Carmichael, S.J.; Day, R.O.; Tett, S.E. A cross-sectional study of hydroxychloroquine concentrations and effects in people with systemic lupus erythematosus. Intern. Med. J. 2013, 43, 547-553. [CrossRef] [PubMed]

22. Noe, G.; Amoura, Z.; Combarel, D.; Lori, L.; Tissot, N.; Seycha, A.; Funck-Brentano, C.; Zahr, N. Development and validation of a fast ultra-high performance liquid chromatography-fluorescent method for the quantification of hydroxychloroquine and its metabolites in patients with lupus. Ther. Drug Monit. 2019, 41, 476-482. [CrossRef] [PubMed]

23. McCune, J.S.; Bemer, M.J.; Barrett, J.S.; Scott Baker, K.; Gamis, A.S.; Holford, N.H. Busulfan in infant to adult hematopoietic cell transplant recipients: A population pharmacokinetic model for initial and Bayesian dose personalization. Clin. Cancer Res. 2014, 20, 754-763. [CrossRef] [PubMed] 